\title{
The influence of strategic consensus among enterprises on supply chain financing performance
}

\author{
Zhengdong $\mathrm{Li}^{1}$, Xuan Guo ${ }^{1, *}$ \\ ${ }^{1}$ School of Humanities, Shanghai University of Technology, Shanghai, China
}

\begin{abstract}
Based on the cognitive behavior theory, this study builds a "cognitive-behavior-performance" model to analyze the path that strategic consensus among enterprises influences supply chain financing performance through supply chain integration, and the moderating role of strategic flexibility in it. The analysis was performed using SPSS. Based on the data of 469 small and medium-sized enterprises, the results show that:(1) the stronger the strategic consensus among enterprises, the higher the performance of supply chain financing;(2) strategic consensus among enterprises can promote supply chain financing performance through supply chain integration;(3) strategic flexibility is beneficial to enhance the positive effect of supply chain integration on supply chain financing performance. This means that SMEs should enhance strategic mutual trust and cooperation and communication with core enterprises, strengthen their competitiveness to improve the integration level of supply chain, and pay attention to the changes of external environment to maintain strategic flexibility, so as to lay a solid foundation for the improvement of supply chain financing performance.
\end{abstract}

\section{Introduction}

As the largest and most active part of the market, SMEs are an important part of China's economic development. However, the development of small and medium-sized enterprises has been difficult, expensive financing and other problems shackles. This is mainly due to the constraints of small and medium-sized enterprises' short operation time, small scale, few mortgageable assets and other factors, as well as the existence of certain information asymmetry between small and medium-sized enterprises and financial institutions, leading to a lot of information of small and medium-sized enterprises is difficult to quantify evaluation, difficult to meet the loan standards of financing institutions. Under this background, supply chain finance appears. The supply chain finance business mainly focuses on the core enterprises of the supply chain and cooperates with commercial banks and other financial institutions. Small and medium-sized enterprises in the supply chain nodes obtain financing opportunities through the help of the core enterprises ${ }^{[1]}$. Supply chain finance mainly focuses on the transaction credibility of enterprises in the whole supply chain structure, that is, the real operating status of the transaction business and financial situation between enterprises ${ }^{[2]}$. Supply chain financing emphasizes the trust and cooperation between enterprises, and a solid strategic partnership will improve the financing performance. Therefore, strategic consensus plays an important role in improving the performance of supply chain financing. Strategic consensus refers to a cognitive state, which is the recognition of industrial development strategy between enterprises and important stakeholders such as customers and suppliers, which is the premise of trust and cooperation between enterprises. It is believed that cognition determines individual behavior, which not only applies to the individual level, but also exists at the organizational level ${ }^{[3]}$. Enterprises are rational strategic decision-making bodies. Therefore, SMEs can reach strategic consensus with core enterprises on the values of market development and cooperation, so as to establish sustainable and stable strategic partnership. Strategic consensus is the driving force of cooperation between enterprises and constantly promotes the development of supply chain. So, supply chain integration as a very important link in the process of supply chain management, is an important factor affecting the performance of supply chain financing. Based on a review of existing studies, there is still no study on the impact of strategic consensus among enterprises on supply chain financing performance from the perspective of supply chain. Based on the cognitive behavior theory, this study builds a "cognitive-behavior-performance" model, explores the way that strategic consensus among enterprises influences supply chain financing performance through supply chain integration, and the moderating role of strategic flexibility in this way, so as to provide reference for supply chain finance in theory and practice.

* Corresponding author: 842355737@qq.om 


\section{Materials and Methods}

\subsection{Strategic consensus among enterprises and supply chain financing performance}

Initially, strategic consensus mainly refers to the consensus and understanding of the organization strategy among the individuals in the team. Later, the research scope of strategic consensus has been continuously expanded and also applied to organizations. It means that enterprises, as rational decision-making subjects, believe that cooperation is more conducive to long-term development and reach strategic consensus on aspects concerning mutual interests such as market development and process management ${ }^{[4-5]}$. Among them, strategic mutual trust and cooperative communication are two important dimensions to measure strategic consensus. Different from the traditional financing business, in the process of supply chain financing, there are many subjects participating in the business network. In addition to the financial institutions such as banks, the core enterprises in the supply chain can also provide loans to the upstream and downstream small and medium-sized enterprises ${ }^{[6-7]}$. Supply chain financing performance includes three aspects: financing cycle, capital amount and cost ${ }^{[8]}$. Therefore, once SMEs have good strategic mutual trust and cooperative communication with core supply chain enterprises, it means that both sides have a stronger sense of responsibility to solve problems jointly, and will give more help to each other in addition to the fulfillment of contract and treaty.

On the one hand, the strengthening of strategic mutual trust between small and medium-sized enterprises and core enterprises in the supply chain can enhance the stickiness of bilateral cooperation and make the strategic cooperative relationship more stable, thus laying a solid foundation for financing. Both parties with a good cooperative relationship will bring the benefit return expected from the strategy and reduce the probability of default and other events. It can not only improve their financing credit by relying on the core enterprise, but also improve the development of SMEs and enhance their ability to repay. On the other hand, good cooperation and communication between SMEs and core enterprises can reasonably reduce the cost of coordination and communication, laying a good foundation for further cooperation. Furthermore, frequent communication with suppliers, customers and other partners can help SMEs more accurately grasp the market demand information. Based on the common judgment of market changes, SMEs can better meet the needs of their partners. Therefore, small and medium-sized enterprises can have good reputation and stable development, so as to obtain financial support from core enterprises and various financing institutions and improve financing performance. To sum up, the following research hypotheses are proposed:

H1: Strategic consensus among enterprises positively influences supply chain financing performance

H1a: Strategic mutual trust between enterprises positively influences supply chain financing performance
H1b: Cooperative communication between enterprises positively influences supply chain financing performance

\subsection{The mediating role of external integration of supply chain}

Supply chain integration is the process of unified management of all information resources and internal and external processes of enterprises on the supply chain through strategic cooperation between enterprises. At present, there is no unified conclusion on the concept of supply chain integration, which can be roughly divided into two parts: internal integration of supply chain and external integration of supply chain. This paper mainly studies the external integration of supply chain. External integration of supply chain refers to the process in which enterprises conduct cooperative transactions with customers and suppliers to achieve strategic consistency among enterprises ${ }^{[9]}$. When enterprises reach strategic consensus, based on common values and transaction norms, it is helpful to avoid the occurrence of asymmetric information between enterprises and improve the degree of cognitive consistency between them. Furthermore, when enterprises have a very deep cognitive accumulation, it is easier for them to carry out cooperation to promote the external integration level of the supply chain. On the one hand, when enterprises have strategic mutual trust and reach an agreement to solve common problems, the sense of community belief among enterprises will be strengthened, and the external integration of supply chain will be optimized accordingly Moreover, the level of trust will also affect the cost of external integration of the supply chain ${ }^{[10]}$. On the other hand, good cooperative communication can improve the degree of information sharing among enterprises. As the frequency of information communication keeps increasing, the external integration of enterprises' supply chains will also be improved.

At the same time, in the supply chain, the size of small and medium-sized enterprises is small, and the development of their various businesses mainly depends on the development degree of the whole supply chain. When the external integration degree of the supply chain is high, small and medium-sized enterprises will better realize the circulation and utilization of resources. The development of supply chain finance is mainly based on the cooperative relationship between strategic partners to improve the financing efficiency of small and medium-sized enterprises. Studies have shown that the external integration of supply chain has a significant positive impact on enterprise financing performance ${ }^{[11]}$. Some studies point out that supply chain integration is the best solution to realize supply chain financing mode based on the coordination and integration of funds and information among enterprises ${ }^{[12]}$. Therefore, the higher the degree of integration between SMEs and enterprises at the nodes of the supply chain, especially when they have a good cooperative relationship with core enterprises, the higher their financing performance will be. In conclusion, the following hypotheses are proposed: 
H2: Strategic consensus among enterprises positively influences the external integration of supply chain

H2a: Strategic trust among enterprises positively affects the external integration of supply chain

$\mathrm{H} 2 \mathrm{~b}$ : Cooperative communication among enterprises positively influences the external integration of supply chain

H3: Supply chain external integration plays an intermediary role between strategic consensus among enterprises and supply chain financing performance

$\mathrm{H} 3 \mathrm{a}$ : External integration of supply chain plays an intermediary role in the relationship between strategic trust among enterprises and supply chain financing performance

$\mathrm{H} 3 \mathrm{~b}$ : External integration of supply chain plays an intermediary role between cooperation and communication among enterprises and supply chain financing performance

\subsection{The regulatory effect of strategic flexibility}

In the current uncertain environment, strategic flexibility, as an important driving force for enterprises to enhance their competitive advantages, can use their own resources and cooperative operation capabilities to defend against risks for enterprises. Strategic flexibility is a kind of high order dynamic ability ${ }^{[13]}$. It refers to the ability to adapt to the environment by actively identifying changes in external relations or policies in order to grasp development opportunities in an uncertain environment and reconfiguring enterprise resources and strategic direction ${ }^{[14]}$. Especially for small and medium-sized enterprises with weak foundation and poor risk resistance ability, flexible strategy can provide support for the development of small and medium-sized enterprises, and enable them to maximize their own resources to form competitive advantages. Supply chain network is very complex and changeable. In the process of supply chain integration, various relationships and resources need to be adjusted to adapt to the operation of business activities. Those small and medium-sized enterprises with strategic flexibility are flexible and diversified, with higher degree of integration of external resources and more agile execution, so it is easier to realize coordinated operation of funds and information. Strategic flexibility provides SMEs with the ability to cope with change. Supply chain integration is constantly optimized and improved with the change of the environment, which will be more conducive to the improvement of supply chain financing performance. Accordingly, the following hypotheses are proposed:

H4: Strategic flexibility positively moderates the relationship between supply chain external integration and supply chain financing performance

\section{Results \& Discussion}

\subsection{Samples and data}

The research objects are small and medium-sized enterprises in Shanghai, Jiangsu, Anhui, Henan and other regions that obtain financing through supply chain finance. The research team adopted the method of electronic questionnaire survey, a total of 600 questionnaires were sent out and 512 questionnaires were recovered. After excluding invalid questionnaires with missing values, outliers and excessive repetitive values, 469 questionnaires were obtained with effective recovery of $91.6 \%$.

\subsection{Variable measurement.}

In terms of the measurement methods of variables such as strategic consensus among enterprises, external integration of supply chain, performance of supply chain financing and strategic flexibility, this study used mature scales at home and abroad for reference to ensure the reliability and validity of the questionnaire measurement. Except for the control variables, Likert 5-point scale was used for all the variables studied.

(1) Strategic consensus among enterprises. Referring to the measurement scale of Romijn \& Albaladejom ${ }^{[15]}$, Luo ${ }^{[16]}, \mathrm{Xu}$ Ting and Yang Jianjun [17], from two dimensions of strategic mutual trust and cooperative communication, for example, "supply chain enterprises can trust each other in respect of complying with the strategic cooperation agreement". And other 8 items, including 1 reverse question. The Cronbach's $\alpha$ value of the scale was 0.911 and 0.893 .

(2) External integration of supply chain. Drawing on the relevant research of Flynn and other scholars [18], three items are set to measure it, such as "We strive to establish cooperative relations with suppliers and customers". The Cronbach's $\alpha$ value of the scale was 0.879 .

(3) Supply chain financing performance. Supply chain financing performance refers to the measurement method of Song Hua and Lu Qiang, for example [8], "the possibility of obtaining funds with the help of core enterprises is high", a total of 4 items. The Cronbach's $\alpha$ value of the scale was 0.89 .

(4) Strategic flexibility. The measurement scale refers to the research scale of Sanchez ${ }^{[19]}$ and Yang Zhuoer ${ }^{[20]}$ et al, consisting of 8 items, such as "the same resource is highly shared among various departments within the company". The Cronbach's $\alpha$ value of the scale was 0.902 .

(5) Control variable. Operating life of the enterprise, Enterprise scale, Annual sales, Total assets.

\subsection{Data processing}

\subsubsection{Common method bias}

In order to test whether the data samples have the problem of homology deviation, Harman single-factor test method is used to test the common method deviation of the major research variables in the data, such as strategic consensus among enterprises, external integration of supply chain, financing performance of supply chain and strategic flexibility. The analysis results show that the factor analysis of 23 items shows that the 
maximum explanatory variation degree of the factor is $32.37 \%$, indicating that there is no serious homology deviation in the data samples, which will not affect the reliability of the study.

\subsubsection{Descriptive statistics}

Then, the correlation between strategic consensus among enterprises, external integration of supply chain, performance of supply chain financing and strategic flexibility is analyzed, and the results are shown in Table
1. Strategic trust had a positive effect on supply chain financing performance $(\beta=0.355, \mathrm{P}<0.01)$, and strategic trust had a positive effect on external integration of supply chain $(\beta=0.508, \quad \mathrm{P}<0.01)$. Cooperative communication positively affected supply chain financing performance $(\beta=0.530, \quad \mathrm{P}<0.01)$, and cooperative communication positively affected external integration of supply chain $(\beta=0.382, \mathrm{P}<0.01)$. External integration of supply chain was positively correlated with supply chain financing performance $(\beta=0.390, \mathrm{P}<0.01)$.

Table 1 Descriptive statistical analysis

\begin{tabular}{ccccccccccc}
\hline Variable $(\mathrm{N}=469)$ & $\mathrm{M}$ & $\mathrm{SD}$ & 1 & 2 & 3 & 4 & 5 & 6 & 7 & 8 \\
\hline OL & 1.486 & 0.500 & 1 & & & & & & \\
ES & 2.580 & 1.748 & -0.013 & 1 & & & & & \\
AS & 1.985 & 0.705 & $-.119^{*}$ & $-.296^{* *}$ & 1 & & & & \\
TA & 2.559 & 1.383 & $-.168^{* *}$ & $.783^{* *}$ & $-.226^{* *}$ & 1 & & & \\
SMT & 3.348 & 0.674 & $-.158^{* *}$ & .042 & $.156^{* *}$ & .078 & 1 & & \\
CC & 3.546 & 0.610 & $-.112^{*}$ & .042 & .088 & $.094^{*}$ & $.288^{* *}$ & 1 & & \\
EI & 3.493 & 0.786 & $-.168^{* *}$ & .076 & .045 & $.101^{*}$ & $.508^{* *}$ & $.382^{* *}$ & 1 \\
FP & 3.413 & 0.657 & $-.225^{* *}$ & $.102^{*}$ & .081 & $.170^{* *}$ & $.355^{* *}$ & $.530^{* *}$ & $.390^{* *}$ & 1 \\
SF & 3.699 & 0.641 & $-.134^{* *}$ & $.119^{* *}$ & .086 & $.176^{* *}$ & $.372^{* *}$ & $.632^{* *}$ & $.406^{* *}$ & $.568^{* * *}$ \\
\hline
\end{tabular}

$* \mathrm{p}<0.05, * * \mathrm{p}<0.01$

(Operating life of the enterprise: OL; enterprise scale: ES; annual sales: AS; total assets: TA; Strategic mutual trust: SMT; Cooperation and communication: CC; External integration of supply chain: EI; Supply chain financing performance: FP; Strategic flexibility: SF)

\subsubsection{Hypothesis and model testing}

(1) Strategic consensus among enterprises and supply chain financing performance. In this study, Baron hierarchical regression analysis was used to test each hypothesis. The results are shown in Table 2. According to Model 1, strategic trust has a positive impact on supply chain financing performance $(\beta=0.315, \mathrm{P}<0.001)$, and $\mathrm{H} 1 \mathrm{a}$ is verified. It can be seen from Model 3 that cooperative communication has a positive effect on supply chain financing performance $(\beta=0.500, p<0.001)$. Hypothesis $\mathrm{H} 1 \mathrm{~b}$ is verified. To sum up, hypothesis $\mathrm{H} 1$ holds, that is, strategic consensus among enterprises promotes supply chain financing performance, and strengthening strategic consensus among enterprises in the supply chain network helps small and medium-sized enterprises improve financing performance.

(2) Test the mediating effect of supply chain external integration. The test results are shown in Table 2. Firstly, the external integration of supply chain is taken as the outcome variable to obtain Model 6 and Model 7 . According to Model 6, strategic trust positively affects the external integration of supply chain $(\beta=0.495, \mathrm{P}<$ 0.001 ), and the hypothesis $\mathrm{H} 2 \mathrm{a}$ is verified. According to Model 7, cooperative communication is significantly positively correlated with external integration of supply chain $(\beta=0.495, \mathrm{P}<0.001)$, and the hypothesis $\mathrm{H} 2 \mathrm{~b}$ is verified. In summary, hypothesis $\mathrm{H} 2$ is supported, that is, strategic consensus among enterprises can have a positive impact on supply chain integration, which supports the next mediation effect test. Then, taking supply chain financing performance as the outcome variable, model 1 , model 2 , model 3 , model 4 and model
5 are obtained. As can be seen from Model 1, strategic mutual trust has a positive impact on supply chain financing performance $(\beta=0.315, \mathrm{p}<0.001)$. As can be seen from Model 6, strategic mutual trust has a positive impact on the external integration of supply chain $(\beta=0.495, p<0.001)$. The external integration of supply chain has a significant positive correlation with supply chain financing performance $(\beta=0.351, \mathrm{P}<0.001)$. In Model 2, the positive effect of strategic trust degree on supply chain financing performance is significantly smaller $(\beta=0.185, \mathrm{P}<0.001)$, and the external integration of supply chain still has a significant positive effect on supply chain financing performance $(\beta=0.261, \mathrm{P}<0.001)$. The above analysis shows that the external integration of supply chain plays a partial mediating role between strategic trust and supply chain financing performance, and hypothesis $\mathrm{H} 3 \mathrm{a}$ is verified. Model 3 shows that cooperative communication has a positive effect on supply chain financing performance $(\beta=0.500, \mathrm{P}<0.001)$. Model 7 shows that cooperative communication has a positive effect on supply chain external integration $(\beta=0.364, \quad P<0.001)$. In Model 4, cooperative communication has a smaller positive effect on supply chain financing performance $(\beta=0.430, \mathrm{P}<0.001)$; the external integration of supply chain still has a positive impact on supply chain financing performance $(\beta=0.194$, $\mathrm{P}<0.001)$. The above analysis shows that the external integration of supply chain plays a partial mediating role between cooperative communication and supply chain financing performance, and hypothesis $\mathrm{H} 3 \mathrm{~b}$ is verified. In conclusion, hypothesis H3 is supported, that is, strategic consensus among enterprises can promote supply chain financing performance through the external 
integration of supply chain.

Table 2 Test results of direct effect and mediating effect

\begin{tabular}{|c|c|c|c|c|c|c|c|}
\hline \multirow{2}{*}{ Variable } & \multicolumn{5}{|c|}{ FP } & \multicolumn{2}{|c|}{ EI } \\
\hline & M1 & M2 & M3 & M4 & M5 & M6 & M7 \\
\hline \multicolumn{8}{|l|}{$\begin{array}{l}\text { Control } \\
\text { variable }\end{array}$} \\
\hline $\mathrm{OL}$ & $-0.148 * *$ & $-0.124 * *$ & $\begin{array}{l}-0.148 * * \\
*\end{array}$ & $-0.124 * *$ & $-0.134 * *$ & $-0.090 *$ & $-0.125^{* *}$ \\
\hline ES & -0.006 & -0.016 & 0.021 & 0.008 & -0.013 & 0.036 & 0.066 \\
\hline AS & 0.043 & 0.051 & 0.047 & 0.044 & 0.078 & -0.030 & 0.017 \\
\hline $\mathrm{TA}$ & 0.136 & 0.132 & 0.092 & 0.093 & $0.140 *$ & 0.013 & -0.003 \\
\hline \multicolumn{8}{|l|}{$\begin{array}{l}\text { Independent } \\
\text { variable }\end{array}$} \\
\hline SMT & $\begin{array}{l}0.315^{* *} \\
*\end{array}$ & $\begin{array}{l}0.185 * * \\
*\end{array}$ & & & & $\begin{array}{l}0.495 * * \\
*\end{array}$ & \\
\hline $\mathrm{CC}$ & & & $\begin{array}{l}0.500 * * \\
*\end{array}$ & $0.430 * * *$ & & & $0.364 * * *$ \\
\hline \multicolumn{8}{|l|}{$\begin{array}{l}\text { Mediating } \\
\text { variable }\end{array}$} \\
\hline EI & & $\begin{array}{l}0.261 * * \\
*\end{array}$ & & $0.194 * * *$ & $0.351 * * *$ & & \\
\hline $\mathrm{R}^{2}$ & 0.171 & 0.221 & 0.320 & 0.351 & 0.196 & 0.269 & 0.165 \\
\hline $\begin{array}{c}\text { After } \\
\text { adjusting } \mathrm{R}^{2}\end{array}$ & 0.162 & 0.211 & 0.313 & 0.343 & 0.187 & 0.261 & 0.156 \\
\hline F & $\begin{array}{l}19.090 * \\
* *\end{array}$ & $\begin{array}{l}21.800 * \\
* *\end{array}$ & $\begin{array}{l}43.588 * \\
* *\end{array}$ & $\begin{array}{l}41.701 * * \\
*\end{array}$ & $\begin{array}{c}22.563^{* *} \\
*\end{array}$ & $\begin{array}{l}34.124 * \\
* *\end{array}$ & $\begin{array}{l}18.358 * * \\
*\end{array}$ \\
\hline
\end{tabular}

(3) The regulating effect of strategic flexibility. Taking supply chain financing performance as the outcome variable, Model 8, Model 9 and Model 10 are obtained. The results are shown in Table 3. It can be seen from Model 8 that external integration of supply chain has a positive impact on supply chain financing performance $(\beta=0.351, \mathrm{P}<0.001)$, and the results of Model 9 shows that strategic flexibility has a significant positive impact on supply chain financing performance $(\beta=0.527, \quad P<0.001)$. Finally, in Model 10 , the interaction terms of supply chain external integration and strategic flexibility have a significant positive impact on supply chain financing performance $(\beta=0.551, \mathrm{p}<0.001)$. Hypothesis $\mathrm{H} 4$ is verified.

\section{Conclusions}

The research draws the following conclusions: the stronger the strategic consensus among enterprises, the higher the performance of supply chain financing; strategic consensus among enterprises can promote supply chain financing performance through supply chain integration; strategic flexibility is beneficial to enhance the positive effect of supply chain integration on supply chain financing performance. It can be seen that the improvement of supply chain financing performance is not only directly related to strategic flexibility, but also depends on the external integration of supply chain and the role of strategic flexibility in it. Therefore, the following enlightenment can be obtained:(1) small and medium-sized enterprises should actively seek to establish strategic consensus with supply chain partners. Strategic mutual trust among supply chain enterprises can realize information sharing and joint learning, so as to help small and medium-sized enterprises better cope with future uncertain risks and improve financing performance. When there is a stable and smooth communication channel, all kinds of resources in the supply chain will operate quickly, improve the efficiency of the completion of various businesses, and effectively avoid opportunistic risks, so as to achieve the performance of supply chain financing; (2) small and medium-sized enterprises should actively seek the integration of external resources. Specifically, the higher the external integration level of the supply chain, the more business transaction information the core enterprises have, the more real information they will be able to provide to financial institutions in the financing of SMEs, which will help improve the financing performance; (3) strategic flexibility plays a defensive role in the changing environment at present. Therefore, SMEs should focus on resources and coordinated flexible mechanism to improve the performance of supply chain financing.

Table 3 Test results of regulatory effect

\begin{tabular}{cccc}
\hline Variable & & FP & \\
\cline { 2 - 4 } & M8 & M9 & M10 \\
\hline Control variable & & &
\end{tabular}




\begin{tabular}{|c|c|c|c|}
\hline OL & $-0.134 * *$ & $-0.103 * *$ & $-0.101 * *$ \\
\hline ES & -0.013 & -0.002 & -0.007 \\
\hline AS & 0.078 & 0.001 & -0.008 \\
\hline $\mathrm{TA}$ & $0.140^{*}$ & 0.048 & 0.031 \\
\hline \multicolumn{4}{|l|}{ Independent variable } \\
\hline EI & $0.351 * * *$ & $0.149 * * *$ & $0.098 *$ \\
\hline \multicolumn{4}{|l|}{ Mediating variable } \\
\hline SF & & $0.527 * * *$ & 0.052 \\
\hline \multicolumn{4}{|l|}{ Interaction term } \\
\hline $\mathrm{EI} \times \mathrm{SF}$ & & & $0.551 * * *$ \\
\hline $\mathrm{R}^{2}$ & 0.196 & 0.414 & 0.463 \\
\hline After adjusting $\mathrm{R}^{2}$ & 0.187 & 0.406 & 0.455 \\
\hline $\mathrm{F}$ & $22.563 * * *$ & $54.297 * * *$ & $56.891 * * *$ \\
\hline
\end{tabular}

\section{Acknowledgments}

Phase results of the general project of Shanghai Philosophy and Social Science Planning Fund "Research on the risk management and crisis intervention of workplace stress in urban high-tech parks" (2018BSH013)

\section{References}

1. Wuttke D. A., Blome C., Foerstl K., et al. Managing the innovation adoption of supply chain finance [J].Journal of Business Logistics, 2013, 34(2): 148-166

2. Wandfluh M., Hofmann E., Schoensleben P. Financing Buyer-Supplier Dyads: An Empirical Analysis on Financial Collaboration in the Supply Chain. International Journal of Logistics Research and Applications, 2016, 19(3): 1-18.

3. Bandura A. Social foundations of thought and action: a social cognitive theory [M]. NJ: Pearson Education, 1986.

4. Zaisheng. H. A Review of Strategic Consensus Theory $[\mathrm{J}]$. Foreign Economics and Management, 2010, 32(3): 11-17+39.

5. Hong W, Chuanming C. The impact of entrepreneurial social capital on strategic consensus among stakeholders [J]. Nanjing Social Sciences, 2013, 24(10): 21-28.

6. Hofmann E. Supply Chain Management: Strategy, Planning and Operations [J]. Journal of Purchasing and Supply Management, 2013, 19(3): 212-213.

7. Hofmann E. Supply Chain Finance: Some Conceptual Insights [J /OL]. Lasch R., Janker C. G. (Hrsg.), Logistik Management-Innovation Logistikkonzepte, 2005, S: 203-214

8. Hua S, Qiang L. What kind of SMEs can benefit from supply chain finance? - A Network and Capability Perspective [J]. Management World, 2017, (6): 104-121.

9. Baofeng H, Zhi C, Siyu L, et al. Research on the Matching of Supply Chain Internal Integration and External Integration [J]. Systems Engineering
Theory \& Practice, 2016, 36(2): 363-373.

10. Robert B., Ortmeyer G. Channel partnerships streamline distribution [J]. Sloan Management Review, 2002, 12(3): 55-96.

11. Xiaohong C. An empirical study on the impact of supply chain integration on the performance of manufacturing enterprises: A case study of manufacturing enterprises in Hunan Province [J]. Accounting Bulletin: Integrated (2), 2010.

12. Guoping L. Research on Supply Chain Financing Mode and Risk Control of High-tech Enterprises [D]. Tianjin: Nankai University, 2013.

13. Kandemir D., Acur N. Examining Proactive Strategic Decision-Making Flexibility in New Product Development [J]. Journal of Product Innovation Management, 2012, 29(4): 608-622.

14. Zhou K. Z., Wu F. Technological capability, strategic flexibility, and product innovation [J]. Strategic Management Journal, 2010, 31(5): 547-561.

15. Romijn H., Albaladejom. Determinants of innovation capability in small electronics and software firms in southeast England [J]. Research Policy, 2002, 31(7): 1053-1067.

16. Luo Y. Procedural fairness and interfirm cooperation in strategic alliances [J]. Strategic Management Journal, 2008, 29(1): 27-46.

17. Ting X., Jianjun Y., The role of inter-firm trust, cooperation model and cooperative innovation performance: the moderating role of knowledge base compatibility [J]. East China Economic Management, 2017 (12): 35-43.

18. Flynn B B., Huo B., Zhao X. The impact of supply chain integration on performance: A contingency and configuration approach [J]. Journal of Operation Management, 2010.

19. Sanchez R. Strategic Flexibility in Product Competition [J]. Strategic Management Journal, 1995, 16(1): 135-159.

20. Zhuoer Y, Shanhang G, Nan Z. The moderating role of strategic flexibility in the impact of exploratory innovation and applied innovation on environmental uncertainty [J]. Science Research Management, 2016, 37(1): 1-10. 